\title{
Simultaneous penalty free dual wavelength conversion using four wave mixing in a semiconductor optical amplifier
}

\section{Citation for published version (APA):}

Raz, O., Gallep, C. M., \& Dorren, H. J. S. (2009). Simultaneous penalty free dual wavelength conversion using four wave mixing in a semiconductor optical amplifier. In Proceedings of the 2009 IEEE LEOS Annual Meeting Conference, (LEOS '09) 4 - 8 October 2009, Belek-Antalya (pp. WK2-469/470). Institute of Electrical and Electronics Engineers. https://doi.org/10.1109/LEOS.2009.5343186

DOI:

10.1109/LEOS.2009.5343186

Document status and date:

Published: 01/01/2009

\section{Document Version:}

Publisher's PDF, also known as Version of Record (includes final page, issue and volume numbers)

\section{Please check the document version of this publication:}

- A submitted manuscript is the version of the article upon submission and before peer-review. There can be important differences between the submitted version and the official published version of record. People interested in the research are advised to contact the author for the final version of the publication, or visit the $\mathrm{DOI}$ to the publisher's website.

- The final author version and the galley proof are versions of the publication after peer review.

- The final published version features the final layout of the paper including the volume, issue and page numbers.

Link to publication

\section{General rights}

Copyright and moral rights for the publications made accessible in the public portal are retained by the authors and/or other copyright owners and it is a condition of accessing publications that users recognise and abide by the legal requirements associated with these rights.

- Users may download and print one copy of any publication from the public portal for the purpose of private study or research.

- You may not further distribute the material or use it for any profit-making activity or commercial gain

- You may freely distribute the URL identifying the publication in the public portal.

If the publication is distributed under the terms of Article 25fa of the Dutch Copyright Act, indicated by the "Taverne" license above, please follow below link for the End User Agreement:

www.tue.nl/taverne

Take down policy

If you believe that this document breaches copyright please contact us at:

openaccess@tue.nl

providing details and we will investigate your claim. 


\title{
Simultaneous Penalty Free Dual Wavelength Conversion Using Four Wave Mixing in a Semiconductor Optical Amplifier
}

\author{
O. Raz ${ }^{1}$, C.M. Gallep ${ }^{1,2}$, H.J.S. Dorren ${ }^{1}$ \\ 1: COBRA Research Institute, Eindhoven University of Technology, Eindhoven, P.O. Box 513, NL-5600 MB, The Netherlands. \\ 2: Division of Telecomm. Technology - CESET, State University of Campinas, Limeira/SP, P.O. Box 6101, 13484-332, Brazil. \\ Email: o.raz@tue.nl
}

\begin{abstract}
We demonstrate simultaneous wavelength conversion of two 10Gb/s signals of different modulation format (PSK\&ASK) using a single common pump and a highly non-linear Semiconductor Optical Amplifier (SOA). The converted signals had no measurable power penalty.
\end{abstract}

\section{INTRODUCTION}

All-optical wavelength converters (AOWCs) are likely to become essential building blocks for future dynamic highcapacity optical networks [1]. Due to their integration potential and power efficiency, SOAs have attracted considerable research interest as wavelength converters. Errorfree wavelength conversion based on cross-gain and crossphase modulation (XGM, XPM) in a single SOA has been demonstrated at up to $320 \mathrm{~Gb} / \mathrm{s}[2]$. However, using XGM and XPM implies that the same SOA cannot be used to convert signals of different modulation formats or speeds, as required additional manipulation of the signal, implies altering the convertor [2]. Recently[3], a single convertor design has been suggested to perform both DPSK and OOK conversion, however the suggested convertor can only convert one of these modulation formats at any given time, requires more than a single SOA for operation and has a noticeable high penalty for alternating modulation formats.

While XGM and XPM based conversion schemes offer broad band conversion and acceptable penalties, the converted output signal is present at the converters input and output as a CW signal all the time. Thus, in case of packet routing, a continuous interfering signal will exist in the network, unless fast on/off control of the laser is implemented. In contrast, using FWM implies that the generated copy has an exclusive wavelength and is thus only generated when a data packet enters the converter. Such a mechanism can be easily exploited to make self routing of packets.

Several demonstrations of Four Wave Mixing (FWM) in SOAs have been reported over the years [4,5]. In these demonstrations, a strong pump carrying the information, in any modulation format or speed, was converted to one or many (multicast) probes. In this way high efficiency was achieved, but only a single data pattern was copied at any given time. Using a single strong probe with multiple pumps has been also suggested [6], but was only demonstrated for a single modulation format at low bit rates and with considerable penalty.

In this letter we demonstrate how by employing a single strong probe and a single SOA, penalty free conversion, based on FWM is achieved. The strong $\mathrm{CW}$ probe clamps the gain and normally occurring XGM due to variation in power of data carrying pump signals are avoided. By placing two data signals within the effective FWM bandwidth of a highly nonlinear SOA, simultaneous conversion of both input data signals is obtained with no measureable receiver power penalty for either single or simultaneous conversions. Furthermore, the two data channels employ different modulation techniques (PSK and ASK), with no noticeable performance variation between them.

II. SETUP

The experimental set up is shown in Fig. 1.

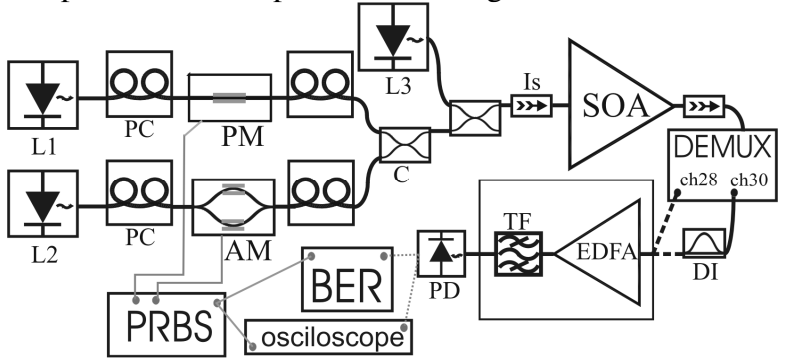

Fig. 1: Schematic diagram of the experimental setup.

Two laser sources at wavelengths $1556.55 \mathrm{~nm}$ and $1558.17 \mathrm{~nm}$ and power levels of -19 and $-16 \mathrm{dBm}$ respectively are modulated with ASK and PSK at a rate of $10 \mathrm{~GB} / \mathrm{s}$ with a NRZ PRBS $2^{31}-1$ data sequence. These two data signals are combined at the input of the SOA with a much stronger $\mathrm{CW}$ probe signal (+2dBm@1555.75nm). The SOA is biased at $500 \mathrm{mAmps}$ and has a saturation output power of $15 \mathrm{dBm}$ and a small signal gain $>30 \mathrm{~dB}$. The selection of input wavelength, on the ITU WDM gird, was done in order to achieve mixing products also on the ITU WDM grid which can be easily filtered with a $100 \mathrm{GHz}$ DWDM Demultiplexer. Once filtered the signals are further amplified by a low noise EDFA amplifier with a gain of $10 \mathrm{~dB}$ and a noise figure of $4 \mathrm{~dB}$ and another tunable $1.5 \mathrm{~nm}$ wide filter is used to remove excessive ASE. While the converted ASK signal at a wavelength of 
$1554.94 \mathrm{~nm}$ can be directly detected after amplification, the PSK converted signal @ 1553.33nm is sent through a Delayed Interferometer (DI) for conversion into amplitude modulation before detection. The photo-diode output is sent to a Bit Error Detector (BER) to measure the performance.

\section{WORKING PRINCIPLE}

Four Wave Mixing is a $\chi^{3}$ non linearity which is proportional to the combination of three optical fields. A degenerate version of this process can be achieved with only two signals, designated pump (data modulated signal) and probe (cw laser light). For the degenerate case, the resulting stokes and antistokes spectral products take the frequency given by $2 \omega_{\text {pump }}-\omega_{\text {probe }}$ and $2 \omega_{\text {probe }}-\omega_{\text {pump }}$ and have a relative power given by $E_{\text {pump }}^{2} \cdot E_{\text {probe }}$ or $E_{\text {probe }}^{2} \cdot E_{\text {pump }}$ respectively. The power of the generated stokes components also depends on the detuning between the pump and probe as the process requires phase matching of the respective $k$ vectors which degrades as the fields are more separated spectrally. Since the generated degenerate FWM product may depends on the intensity of the pump signal, the pump signals in our experiment, which had a lower power, were always placed at a lower frequency relative to the probe signal so that when a stronger probe is used (as is the case for this demonstration) phase information is preserved. A typical spectral image of input and output spectra's is given in figure two, showing the strong probe and two weak pumps (at longer wavelengths) at the input and the multitude of FWM products at the output. The spacing between the two pumps and single probe were chosen to be $200 \mathrm{GHz}$ and $100 \mathrm{GHz}$ respectively in order to avoid any unwanted FWM products to fall on the same wavelengths as desired ones.

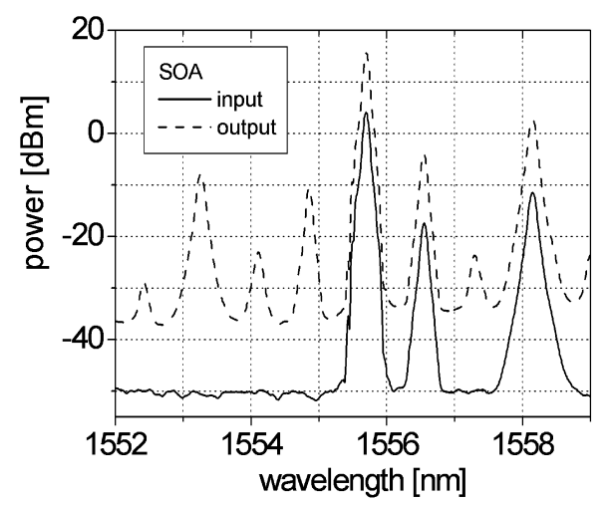

Fig. 2: Spectra's at the input and output of the SOA

\section{RESULTS}

BER measurements of the ASK and PSK pump signal were taken using an 10Gb/s APD receiver with a multiplication factor $M=7$ based on continuous data stream of NRZ coded PRBS $2^{31}-1$. In Fig. 3 measured BER Vs. optical power at the receivers input are traced for both the ASK and PSK modulated signals with and without a simultaneous interfering channel. These are also compared to back to back measurements of the original input channels at wavelengths $1556.55 \mathrm{~nm}$ and $1558.17 \mathrm{~nm}$. From the measured results it is visible that BER of a single converted channel shows no degradation of receiver sensitivity compared to the original data signal. Moreover, even in the presence of a $2^{\text {nd }}$ converted channel the observed degradation of receiver sensitivity is within the measurement error and in any case does not exceed $0.3 \mathrm{~dB}$.

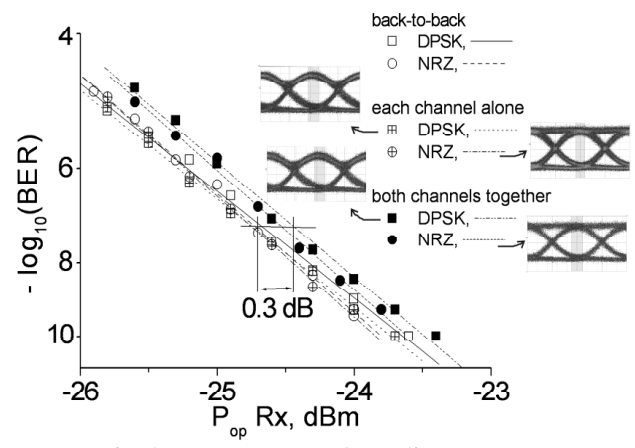

Fig. 3: BER curves and eye diagrams

\section{DISCUSSION AND CONCLUSIONS}

We demonstrate how a single SOA and a single CW laser can be used to convert simultaneously two different data streams with no conversion penalty for single conversion and minimal $<0.3 \mathrm{~dB}$ penalty when a $2^{\text {nd }}$ channel is introduced. The two channels had different modulation techniques and the ASK modulation did not result in XGM, since the relative power of pump signals was $20 \mathrm{~dB}$ lower than the $\mathrm{CW}$ probe, leaving it to insure the SOA operated in deep saturation. Since FWM generates new spectral components only in the presence of pump and probe, the demonstrated converter is suitable for multiple simultaneous conversion schemes, as well as operation in an asynchronous fashion since conversion penalty is almost identical for single or dual inputs. With no need for strict timing control of local CW source, an optional asynchronous operation as well as being modulation format agnostic we believe this scheme for AOWC will find many suitable applications in all optical packet routers.

\section{REFERENCES}

[1] S. L. Danielsen, P. B. Hansen, K. E. Stubkjaer, "Wavelength Conversion in Optical Packet Switching", JLT, Vol. 16, No. 12, pp.2095-2108, 1998

[2] Y. Liu, E. Tangdiongga, Z. Li, H. de Waardt, A. M. J. Koonen, G.D. Khoe and H.J.S. Dorren, Xuewen Shu and Ian Bennion, " Error-free 320 $\mathrm{Gb} / \mathrm{s}$ SOA-based Wavelength Conversionusing Optical Filtering", OFC' 06, PDP28, 2006

[3] X. Yi, R. Yu, J. Kurumida, S.J.B. Yoo, ”Modulation Format Independent Conversion", Proceeding of the OFC 2009, PDPC8, 2009

[4] Akiyama T, Wada O, Kuwatsuka H, Simoyama T, Nakata Y, Mukai K, Sugawara M, Ishikawa H," Nonlinear processes responsible for nondegenerate four-wave mixing in quantum-dot optical amplifiers", Applied physics lett., vol. 77, no. 12, pp. 1753-5, 2000

[5] G. Contestabile, L. Banchi, M. Presi, and E. Ciaramella, "Transparency of FWM in SOAs to Phase/Amplitude and Polarization", OFC'09, OThM6, 2009

[6] J. P. R. Lacey, Member, IEEE, S. J. Madden, and M. A. Summerfield, " Four-Channel Polarization-Insensitive Optically Transparent Wavelength Converter”, IEEE Phot. Tech. Lett., Vol. 9, no. 10, pp.1355-1357, 1997 